\title{
The relationship between perceived milk supply and exclusive breastfeeding during the first six months postpartum: a cross- sectional study
}

\author{
Ayyu Sandhi ${ }^{1,2}$, Gabrielle T. Lee ${ }^{3}$, Roselyn Chipojola², Mega Hasanul Huda ${ }^{2}$ and Shu-Yu Kuo ${ }^{2^{*}}$ (D)
}

\begin{abstract}
Background: Perceived milk supply is an important modifiable factor for optimal breastfeeding. However, little is known about maternal perception of milk supply or how it impacts breastfeeding practices. The aim of this study was to examine relationships of perceived milk supply, maternal breastfeeding self-efficacy, and skin-to-skin contact with early initiation and exclusive breastfeeding among mothers of infants less than 6 months of age in Indonesia.

Methods: This was a cross-sectional study conducted in Yogyakarta City, Indonesia between August and October 2015. Maternal perception of milk supply was assessed using the Hill and Humenick Lactation Scale. Data on breastfeeding practices, and maternal and infant factors were collected using a structured questionnaire. Multiple regression and multivariate logistic regression analyses were performed to obtain estimates of associations.

Results: Thirty four percent of mothers had initiated breastfeeding within an hour after birth, and $62.4 \%$ of mothers were exclusively breastfeeding. High levels of perceived breast milk supply were reported in mothers who practiced skin-to-skin contact or rooming-in with their infants, experienced positive infant sucking behavior, or had high breastfeeding self-efficacy $(p<0.05)$. Mothers with a higher level of perceived milk production (Odds Ratio [OR] 3.20; $95 \%$ Confidence Interval $[\mathrm{Cl}] 1.76,5.83)$ or practicing skin-to-skin contact $(\mathrm{OR} 2.36 ; 95 \% \mathrm{Cl} 1.13,4.91)$ were more likely to exclusively breastfeed, while employed mothers were less likely to breastfeed their infants exclusively (OR $0.47 ; 95 \% \mathrm{Cl} 0.24,0.93)$.

Conclusions: In this study, skin-to-skin contact and breastfeeding self-efficacy are important determinants of perceived milk supply. Higher perception of milk supply was positively linked with exclusive breastfeeding. Our study highlights the importance of the assessment for mother's perception of milk supply, maternal breastfeeding self-efficacy, and skin-to-skin contact in achieving optimal breastfeeding outcomes.
\end{abstract}

Keywords: Breastfeeding, Lactation, Human milk, Breast milk, Perception, Milk supply, Insufficient milk, Postnatal care, Infant feeding, Self-efficacy

\footnotetext{
* Correspondence: sykuo@tmu.edu.tw

${ }^{2}$ School of Nursing, College of Nursing, Taipei Medical University, Taipei,

Taiwan

Full list of author information is available at the end of the article
}

(c) The Author(s). 2020 Open Access This article is licensed under a Creative Commons Attribution 4.0 International License, which permits use, sharing, adaptation, distribution and reproduction in any medium or format, as long as you give appropriate credit to the original author(s) and the source, provide a link to the Creative Commons licence, and indicate if changes were made. The images or other third party material in this article are included in the article's Creative Commons licence, unless indicated otherwise in a credit line to the material. If material is not included in the article's Creative Commons licence and your intended use is not permitted by statutory regulation or exceeds the permitted use, you will need to obtain permission directly from the copyright holder. To view a copy of this licence, visit http://creativecommons.org/licenses/by/4.0/. The Creative Commons Public Domain Dedication waiver (http://creativecommons.org/publicdomain/zero/1.0/) applies to the data made available in this article, unless otherwise stated in a credit line to the data. 


\section{Background}

Breast milk is the optimal nutrition source for neonatal and infant wellbeing [1]. In 2012, the World Health Organization (WHO) established a global target to increase the rates of exclusive breastfeeding in the first 6 months to at least $50 \%$ by 2025 [2]. Recent estimates show that only $37 \%$ of infants aged $0 \sim 5$ months are exclusively breastfed in low- and middle-income countries [3]. Specifically, the duration of exclusive breastfeeding remains a challenge in Indonesia with rates of $42 \%$ in 2012 and 37.3\% in 2018 [4, 5]. Multilevel public health measures have been implemented in Indonesia to improve exclusive breastfeeding rates. For example, a legislation was enacted in 2009 that every baby is breastfed exclusively for the first 6 months of life, unless medically contraindicated [5]. Hospital breastfeeding support was also implemented by following the Ten Steps to Successful Breastfeeding of Baby-Friendly Hospital Initiative (BFHI), including facilitating skin-to-skin contact or rooming-in practice in Indonesian public hospitals [6]. In spite of legislation and hospital efforts, mothers' perceptions of low milk supply and need for formula supplementation were the most common reasons for premature termination of breastfeeding in the immediate postpartum period and up to 6-months [7]. An in-depth understanding of mothers' perception of milk supply and its relation to breastfeeding practices is necessary and will be helpful for developing effective healthcare strategies to improve exclusive breastfeeding rates in Indonesia.

Perception of insufficient milk supply is defined as a maternal belief that her breast milk production is inadequate for her infant's needs [8]. Specifically, mothers often adopt some unreliable signs, such as infant satiety cues or infant crying, as the primary indicator of insufficient milk supply [9], instead of assessing the infant's number of wet diapers and stools [10]. After delivery, mothers who perceive inadequate breast milk production tend to delay initiation of breastfeeding, wait until they believe their breast milk is 'adequate' [11], and may start to introduce unnecessary formula supplementation early [7]. Furthermore, studies suggest that approximately $25 \% \sim 73 \%$ of mothers engage in early unnecessary cessation of breastfeeding due to perceived low milk production $[12,13]$. The early introduction of infant formula will result in a decrease in mothers' milk production, which in turn interrupts their breastfeeding and further causes them to discontinue breastfeeding within the first 6 months postpartum.

Study findings have demonstrated that mothers' perceptions of milk supply are modifiable, and early identification of mothers at risk is important for improving breastfeeding behavior [14]. Studies conducted in Japan and Taiwan found that mothers who were employed, had less than college education [15] or lacked breastfeeding confidence [12] had a significantly low perceived milk supply. The skin-to-skin contact between the mother and newborn is a significant factor in milk production and ejection, and may facilitate exclusive breastfeeding during the hospital stay [16]. However, an integrative review of 20 studies indicated that the prevalence of perceived low milk supply concerning socio-demographic variables or hospital breastfeeding behaviors has not been adequately addressed, and most studies were conducted in Western countries [14].

Maternal perception of milk insufficiency is a global challenge, and its impacts may vary across cultural contexts [14]. It is critical to examine maternal perception of milk supply and relevant factors in a developing country, like Indonesia, where exclusive breastfeeding is essential for infant health. To date, few attempts have been made to identify associated factors in maternal perception of milk supply in Indonesian women, particularly in the community setting where mothers often experience difficulties in breastfeeding after hospital discharge. In response to the WHO's call to increase exclusive breastfeeding and the current low rates of exclusive breastfeeding in Indonesia, the objectives of this study were to identify factors associated with mothers' perceived milk supply and investigate associations between this perception and breastfeeding practices such as early initiation of breastfeeding and exclusive breastfeeding in Indonesia.

\section{Methods}

Design

A cross-sectional study was conducted from August to October 2015 in Yogyakarta City, Indonesia. In total, five public health centers (PHCs) with low exclusive breastfeeding rates, ranging from 14.8 to $25.0 \%$, were selected based on the available estimates in 2009 [17]. Convenience sampling was used to recruit eligible participants who were approached at their residence based on name lists provided by the PHCs. The study was approved by the institutional review board of Universitas Gadjah Mada, Indonesia. Written informed consent was obtained from each mother after the study purpose was explained.

\section{Participants}

Study participants were mother-infant dyads with infants under 6 months of age. Mothers were included in the study if they met the following criteria: were aged $\geq 17$ years, had a singleton pregnancy, had given birth at $\geq 37$ weeks of gestation, had an infant with a birth weight of $\geq 2500 \mathrm{~g}$, and understood and spoke the Indonesian language. Mothers were excluded if they had a history of 
breast surgery, postpartum complications, or their infants had any neonatal anomaly or any admission history to a neonatal intensive care unit. The sample size was estimated based on a prior study on postpartum mothers [18] with an effect size of 0.30 for perception of milk supply. With a significance level of 0.05 and $80 \%$ power in a two-sided $t$-test, the sample size of 176 was needed. Considering an estimated $30 \%$ incompletion rate, a total of 230 mothers were recruited for this study.

\section{Measurements}

Participants completed the self-reported questionnaires after signing the informed consent. It took 20 to $30 \mathrm{~min}$ for each participant to complete the questionnaire. To avoid any missed items, all questionnaires were checked upon their completion.

\section{Translation process}

The Hill and Humenick $(\mathrm{H} \& \mathrm{H})$ Lactation Scale [8], Breastfeeding Self-Efficacy Scale Short Form [19], and infants' sucking behaviors [20] were translated into Bahasa Indonesia following guidelines of Wild et al. [21]. First, a bilingual translator with a qualified health professional background translated the original questionnaires from English into Bahasa Indonesia (forward translation). Two Bahasa Indonesia-speaking experts in the field of postpartum care and breastfeeding then reviewed the translated version for content and precision of the wording to Indonesian culture (reconciliation). Second, the Indonesian version was translated back into English by another independent bilingual qualified translator (back translation). The original and back-translated questionnaires were compared for clarity and consistency by the researchers. Third, the Indonesian versions of the questionnaires were administered to 10 Indonesian mothers to ensure the applicability of the translated questionnaires to the Indonesian population.

\section{Perceived milk supply}

The maternal perception of milk supply was assessed using the $H \& H$ Lactation Scale [8], a 20-item questionnaire with a 7-point Likert scale from 1 (strongly disagree) to 7 (strongly agree). Reverse scoring was applied to items 3 ("Even if I can breastfeed, I would rather not be breastfeeding"), 8 ("I am so upset about breastfeeding problems that I become upset at the thought of breastfeeding"), 12 ("My baby would be hungry if I did not use formula along with breastfeeding"), 13 ("I believe that following breastfeeding with a bottle is how to find out if baby get enough"), 14 ("I would describe my baby as being fussy after breastfeeding"), and 15 ("I feel have to give formula after breastfeeding to satisfy my baby"). Total scores ranged $20 \sim 140$, with higher scores representing a higher perceived milk supply. The total score was re-grouped into dichotomous categories using the mean score of the H\&H Lactation Scale for subsequent analyses. Perceived milk supply was originally assessed as a continuous variable and was dichotomized into low and high perceived milk supply using the mean score for subsequent analyses in order to identify the high-risk group as recommended in previous literature [14]. No missing value was found in this scale in this study. Cronbach's alpha values of the original study ranged $0.91 \sim$ 0.92 [8]. In this study, the content validity index (CVI) of the Indonesian version of the $\mathrm{H} \& \mathrm{H}$ Lactation Scale was 0.99 , and Cronbach's alpha was 0.80 .

\section{Breastfeeding self-efficacy}

The Breastfeeding Self-Efficacy Scale (BSES) Short Form (SF) is a 14-item self-reported questionnaire refined from the original BSES [19], that measures breastfeeding self-efficacy on a 5-point Likert scale from 1 (not at all confident) to 5 (very confident). Total possible scores range $14 \sim 70$, with higher scores indicating higher levels of breastfeeding self-efficacy. Cronbach's alpha from the original study was 0.94 [19]. In this study, the CVI of the Indonesian version of the BSES-SF was 0.99, and Cronbach's alpha was 0.90. Breastfeeding self-efficacy, converted to a dichotomous variable with the cut-off point of 50 , has shown to be a valuable predictor for identifying mothers who need breastfeeding support in previous study [22]. The breastfeeding self-efficacy was divided into high $(>50)$ and low $(\leq 50)$ in the current study.

\section{Infant sucking behavior}

Mothers were asked to assess infants' sucking behavior as defined by Mizuno et.al [20]. Five types of infants' sucking behaviors were classified as follows: type 1: infant vigorously and promptly grasps the nipple and sucks energetically; type 2 : infant is so excited and active at the breast, that he/she alternatively grasps or loses the breast; type 3: infant sucks the breast slowly and reluctantly; type 4: infant usually spends a few minutes of mouthing, tastes small amounts of milk before settling down, and breastfeeds very well; and type 5: infant sucks the breast for a few minutes and then rests a few minutes and repeats the behavior pattern alternatively thereafter. Infants' sucking behaviors were regrouped into two categories of positive (types 1, 4, or 5), and negative (type 2 or 3 ) for subsequent analyses. The CVI of the Indonesian version of infant sucking behavior was 0.95 .

\section{Breastfeeding practices}

In this study, we adopted the WHO definitions of breastfeeding practices [23]. The definitions are as follows. 
Early breastfeeding initiation Early breastfeeding is defined as the mother putting her baby to the breast within $1 \mathrm{~h}$ of birth. In this study, initiation of breastfeeding was self-reported by mothers based on their recall.

Exclusive breastfeeding Exclusive breastfeeding is defined as the mother feeding her baby exclusively with breast milk, directly from the breast or expressed, and with no additional foods in the previous $24 \mathrm{~h}$. Mothers were asked to recall what food was given to their infants until the day prior to the survey.

Predominant breastfeeding Predominant breastfeeding is defined as the infant receiving breast milk as the predominant source of nourishment with certain liquids (e.g., water, water-based drinks, fruit juice, and oral rehydration solution, drops, or syrup).

Demographic variables and health indicators Information on demographic characteristics (age, educational level, employment status, and religion), obstetric factors (parity, delivery type, and delivery location), hospital factors (rooming-in practice and skin-to-skin contact), and infant factors (age, gender and birth weight) were collected using structured questionnaires.

\section{Data analysis}

Data were analyzed using the Statistical Package for the Social Sciences for Windows (version 17.0; SPSS, Chicago, IL). Descriptive statistics including the percentage, frequency, mean $(M)$, and standard deviation $(\mathrm{SD})$ were used to report the distribution of the variables. A $t$-test or ANOVA were used to compare the scores between maternal perception of milk supply and potential factors, including maternal characteristics (age, educational level, employment status, religion), obstetric factors (parity, delivery type, delivery location), hospital procedures (rooming-in practice, skin-to-skin contact), infant factors (infant's age, gender, birth weight, infant sucking behavior), and breastfeeding self-efficacy. We used multiple regression to examine the determinants of perceived milk supply. Potential predictors for maternal perception of milk supply were included in the regression model if their bivariate association with perceived milk supply had a $p$-value of $\leq 0.10$. Multicollinearity between independent variables was examined using the Variance Inflation Factor and Tolerance index. A multivariate logistic regression analysis was performed to estimate relationships between perceived milk supply and breastfeeding practices. We first ran the univariate logistic analyses and then included only those variables with $p \leq$ 0.10 or with clinical meaningfulness in the multivariable logistic model.

\section{Results}

In total, 250 eligible mothers with infants aged $0 \sim 5$ months were invited to participate, and 237 completed the questionnaires. The response rate was $94.8 \%$.

\section{Characteristics of study participants and breastfeeding practices}

The average age of the mothers was $30(\mathrm{SD}=5.5)$ years. The majority of the participants had at least high school education $(67.1 \%)$, were not working $(73.0 \%)$, and were Muslims (90.3\%) (Table 1). More than half of the mothers were multiparous (59.9\%), had a normal vaginal delivery $(73.0 \%)$, and had delivered in the hospital (68.8\%). Most of the mothers practiced rooming-in (63.7\%) and skin-to-skin contact (70.0\%) within the first hour after delivery. The average age of the infants was $2.7(\mathrm{SD}=1.6)$ months, and they had an average weight of $3172 \mathrm{~g}(\mathrm{SD}=397)$. Slightly more than half of the babies were girls (53.6\%), and most showed positive sucking behaviors (84.4\%) (Table 1).

Approximately one-third of the mothers (34.2\%) initiated breastfeeding in the first hour, $62.4 \%$ breastfed their babies exclusively at $0-5$ months, and $37.6 \%$ practiced predominant breastfeeding (Table 2). The mean score of perceived milk supply was $122.4 \quad(\mathrm{SD}=10.0)$, with a range of $81 \sim 140$. The mean score of perceived milk supply among mothers of infants aged $4 \sim 5$ months was $123.6(\mathrm{SD}=10.0)$ with the range of $98 \sim 140$, and this was the highest mean score across infant age groups. The participants' mean score on breastfeeding efficacy was 56.4 ( $\mathrm{SD}=7.2)$ with a range of $26 \sim 70$. High breastfeeding self-efficacy (86.9\%) was reported among most participants (Table 2).

\section{Associations between maternal/infant factors with perceived milk supply}

Results of the univariate analysis indicated that rooming-in, skin-to-skin contact, breastfeeding selfefficacy, and infant sucking behavior were significantly associated with perceived milk supply $(p<0.05)$, while mothers' age, educational level, employment, parity, mode of delivery, delivery location, and infants' age, gender, and birth weight were not (Table 3). Mothers' perceptions of milk supply were not significantly different for each infant age group $(p>0.05)$. Considering that $p$ values of employment and parity were < 0.10 , both variables were included in the multivariate analysis. In the multiple linear regression model, skinto-skin contact and breastfeeding self-efficacy remained significantly associated with maternal perception of milk supply $(p<0.02)$ (Table 4$). R^{2}$ and adjusted $R^{2}$ values for this model were 0.21 and 0.19 , respectively. The variance inflation factors for the variables $(1.04 \sim 1.08)$ were not above the value of 10 , 
Table 1 Characteristics of study participants $(N=237)$

\begin{tabular}{|c|c|c|}
\hline Variable & $n$ & $\%$ \\
\hline Age (years), Mean (SD) & $30.0(5.5)$ & \\
\hline$\leq 30$ & 129 & 54.4 \\
\hline$>30$ & 108 & 45.6 \\
\hline \multicolumn{3}{|l|}{ Educational level } \\
\hline High school and less & 159 & 67.1 \\
\hline College and above & 78 & 32.9 \\
\hline \multicolumn{3}{|l|}{ Employment status } \\
\hline Not working & 173 & 73.0 \\
\hline Working & 64 & 27.0 \\
\hline \multicolumn{3}{|l|}{ Religion } \\
\hline Islam & 214 & 90.3 \\
\hline Other & 23 & 9.7 \\
\hline \multicolumn{3}{|l|}{ Parity } \\
\hline Primiparous & 95 & 40.1 \\
\hline Multiparous & 142 & 59.9 \\
\hline \multicolumn{3}{|l|}{ Mode of Delivery } \\
\hline Vaginal delivery/ Instrumental vaginal delivery & 173 & 73.0 \\
\hline Cesarean delivery & 64 & 27.0 \\
\hline \multicolumn{3}{|l|}{ Delivery location } \\
\hline Hospital & 163 & 68.8 \\
\hline Public health center/midwifery clinic & 74 & 31.2 \\
\hline \multicolumn{3}{|l|}{ Rooming-in } \\
\hline No & 86 & 36.3 \\
\hline Yes & 151 & 63.7 \\
\hline \multicolumn{3}{|l|}{ Skin-to-skin contact } \\
\hline No & 71 & 30.0 \\
\hline Yes & 166 & 70.0 \\
\hline Infant's age (months), Mean (SD) & $2.7(1.6)$ & \\
\hline $0 \sim 1$ & 56 & 23.6 \\
\hline $2 \sim 3$ & 95 & 40.1 \\
\hline $4 \sim 5$ & 86 & 36.3 \\
\hline \multicolumn{3}{|l|}{ Infant's gender } \\
\hline Girl & 127 & 53.6 \\
\hline Boy & 110 & 46.4 \\
\hline \multicolumn{3}{|l|}{ Infant's birth weight (g) } \\
\hline$\leq 3000$ & 95 & 40.1 \\
\hline$>3000$ & 142 & 59.9 \\
\hline \multicolumn{3}{|l|}{ Infant sucking behavior } \\
\hline Negative & 37 & 15.6 \\
\hline Positive & 200 & 84.4 \\
\hline
\end{tabular}

Note: SD Standard Deviation

and the tolerance values for all variables in model (0.93-0.96) were not $<0.16$, indicating a lack of multicollinearity between variables.
Association between perceived milk supply and early initiation of breastfeeding

Logistic regression analyses were used to examine how perceptions of the maternal milk supply were associated with early initiation of breastfeeding. We used the mean score to categorize perceived milk supply score into two groups (scores of $\leq 122$ and $>122$ ). In the univariate analysis, the odds ratio (OR) of perceived milk supply was 1.46 (95\% Confidence Interval [CI] 0.85, 2.50, $p>0.05$ ). Results of the multivariate analyses indicated that caesarean delivery (OR 0.13; 95\% CI 0.04, 0.41, $p=0.0001$ ) and skin-to-skin contact (OR 2.81; 95\% CI 1.14, 6.91, $p=$ 0.024 ) were significantly associated with early initiation of breastfeeding. Neither perceived milk supply, education level, employment status, delivery location, nor rooming-in practice were associated with early initiation of breastfeeding (Table 5).

\section{Association between perceived milk supply and exclusive breastfeeding}

In the univariate analysis, perceived milk supply was significantly associated with exclusive breastfeeding (OR 3.58; $95 \%$ CI 2.05, 6.25, $p=0.0001$ ). In the multivariate model, high levels of perceived milk supply (OR 3.20; 95\% CI 1.76, 5.83, $p=0.0001$ ) or skin-to-skin contact (OR 2.36; 95\% CI 1.13, 4.91, $p=0.022$ ) were significantly associated with exclusive breastfeeding, while working mothers were less likely to practice exclusive breastfeeding during $0-5$ months postpartum (OR 0.47; 95\% CI $0.24,0.93, p=0.029)$. Variables of the educational level, mode of delivery, delivery location, and rooming-in were no longer significant (Table 5).

\section{Discussion}

The present study is the first study to investigate mothers' perceptions of milk sufficiency and how their perception was associated with early initiation of breastfeeding and exclusive breastfeeding among motherinfant dyads in Indonesia. The study revealed that mothers who practiced skin-to-skin contact or had high self-efficacy in breastfeeding were more likely to have higher levels of perceived milk supply. Higher levels of perceived milk supply were linked to higher exclusive breastfeeding rates but not to early initiation of breastfeeding. Our study highlights the importance of maternal perception of the milk supply on optimal breastfeeding outcomes.

The rates of exclusive breastfeeding (62.4\%) in our study, to our surprise, were higher than we expected from the statistics provided by these study PHCs (14.8 to $25.0 \%$ ) and were higher than the national estimates (37.3\%) in Indonesia [4]. Nevertheless, the result of this study was consistent with the rates of exclusive breastfeeding $(63.3 \%, 60 \%)$ reported in two recent studies 
Table 2 Characteristics of perceived milk supply, breastfeeding self-efficacy, early initiation of breastfeeding, and exclusive breastfeeding $(N=237)$

\begin{tabular}{|c|c|c|c|c|}
\hline Variable & $n(\%)$ & Mean (SD) & Min & Max \\
\hline Early initiation of breastfeeding & $81(34.2)$ & & & \\
\hline Predominant breastfeeding & 89 (37.6) & & & \\
\hline Exclusive breastfeeding ( $0 \sim 5$ months) & $148(62.4)$ & & & \\
\hline $0 \sim 1$ month & $39(69.6)$ & & & \\
\hline $2 \sim 3$ months & $59(62.1)$ & & & \\
\hline $4 \sim 5$ months & $50(58.1)$ & & & \\
\hline Perception of the milk supply, Mean (SD) & & $122.4(10.0)$ & 81 & 140 \\
\hline $0 \sim 1$ month, Mean (SD) & & $122.0(10.8)$ & 81 & 139 \\
\hline $2 \sim 3$ months, Mean (SD) & & $121.4(9.4)$ & 96 & 139 \\
\hline $4 \sim 5$ months, Mean (SD) & & $123.6(10.0)$ & 98 & 140 \\
\hline Breastfeeding self-efficacy, Mean (SD) & & $56.4(7.2)$ & 26 & 70 \\
\hline$\leq 50$ & $31(13.1)$ & & 26 & 50 \\
\hline$>50$ & $206(86.9)$ & & 51 & 70 \\
\hline
\end{tabular}

Note: SD Standard Deviation, Min Minimum, Max Maximum

conducted in Yogyakarta regions [24, 25], in which the definition for exclusive breastfeeding by WHO during the first 6 months postpartum was adopted. The relatively high exclusive breastfeeding rates in Yogyakarta regions might be related to multilevel breastfeeding interventions launched since 2012, including peer breastfeeding support and lactation counseling [26]. Therefore, these interventions should continue in Yogyakarta regions, and replications of the interventions for other regions with relatively low rates of exclusive are necessary.

\section{Mothers' perception of milk supply}

We found that perception of milk supply was an important factor associated with exclusive breastfeeding in Indonesian mothers. This finding is consistent with previous studies in Turkey [27] and Mexico [9], which reported that the perception of insufficient milk was prevalent in postpartum mothers who did not practice exclusive breastfeeding. In Indonesian culture, mothers tend to believe that small breasts produce smaller amounts of breast milk and older mothers' breast milk is of lower quality [28], which in turn, impact mothers' perceptions of milk insufficiency. The mothers in our study had a higher perception of breast milk (mean score 122.4 in the Hill and Humenick Lactation Scale) in the first 6 months postpartum compared to perceptions of breast milk supply in a previous study conducted in Taiwan when women were 1 week postpartum (mean scores 106.8-108.2) [15]. It is possible that levels of perceived milk supply vary at different postpartum stages, as breast milk might not be fully established at 1 week postpartum [10]. Despite our study having indicated that mothers' perception of milk supply was not significantly different for each infant age group, assessing potential changes in maternal perception of the milk supply over different postpartum stages warrants further research.

\section{Factors associated with perceived milk supply}

In this study, Indonesian mothers who practiced skinto-skin contact not only reported significantly high levels of breast milk sufficiency but also initiated breastfeeding early and breastfed infants exclusively in the first 6 months postpartum. Specifically, skin-toskin contact produces massage-like movements (e.g., touching of the areola and breast skin) to stimulate lactation [29] with increased opportunities for infant suckling, resulting in a surge of plasma oxytocin which triggers the let-down reflex [30]. Experiencing the let-down reflex accompanied by baby suckling also makes a mother perceive that her milk supply is sufficient for her infant [14]. Studies of Egyptian and US mothers also found the positive effect of skin-toskin contact on early initiation of breastfeeding [31] and exclusive breastfeeding [32]. Early skin-to-skin contact is important for optimal breastfeeding practices and therefore, it is essential to support mothers practicing skin to-skin contact at an early stage.

Consistent with the findings of a previous study [33], we found that mothers who practiced rooming-in tend to have higher perception of sufficient milk supply. It is possible that placing the infant close to the mother enables the mother to respond in a timely manner when her infant shows signs of hunger. Uninterrupted mother-infant interactions and close contact also encourage breastfeeding on demand, which in turn, results in more frequent infant suckling that promotes breast milk production [34]. Our findings also confirmed the positive effect of breastfeeding self-efficacy on perceived 
Table 3 Distribution of perceived milk supply $(N=237)$

\begin{tabular}{|c|c|c|c|c|c|c|c|}
\hline \multirow[t]{2}{*}{ Variable } & \multirow[t]{2}{*}{$n$} & \multirow[t]{2}{*}{$\%$} & \multicolumn{5}{|c|}{ Perception of the milk supply } \\
\hline & & & Mean & $S D$ & Min & Max & $p$ value \\
\hline \multicolumn{8}{|l|}{ Age (years) } \\
\hline$\leq 30$ & 129 & 54.4 & 122.3 & 9.7 & 96 & 139 & \multirow[t]{2}{*}{$0.90^{\mathrm{a}}$} \\
\hline$>30$ & 108 & 45.6 & 122.4 & 10.3 & 81 & 140 & \\
\hline \multicolumn{8}{|l|}{ Educational level } \\
\hline High school and less & 159 & 67.1 & 122.1 & 9.5 & 95 & 140 & \multirow[t]{2}{*}{$0.57^{\mathrm{a}}$} \\
\hline College and above & 78 & 32.9 & 122.9 & 10.9 & 81 & 138 & \\
\hline \multicolumn{8}{|l|}{ Employment status } \\
\hline Not working & 173 & 73.0 & 123.1 & 9.7 & 81 & 139 & \multirow[t]{2}{*}{$0.07^{a}$} \\
\hline Working & 64 & 27.0 & 120.5 & 10.5 & 98 & 140 & \\
\hline \multicolumn{8}{|l|}{ Religion } \\
\hline Islam & 214 & 90.3 & 122.3 & 9.7 & 95 & 140 & \multirow[t]{2}{*}{$0.77^{a}$} \\
\hline Other & 23 & 9.7 & 122.9 & 12.1 & 81 & 135 & \\
\hline \multicolumn{8}{|l|}{ Parity } \\
\hline Primiparous & 95 & 40.1 & 120.9 & 10.4 & 96 & 139 & \multirow[t]{2}{*}{$0.06^{a}$} \\
\hline Multiparous & 142 & 59.9 & 123.4 & 9.6 & 81 & 140 & \\
\hline \multicolumn{8}{|l|}{ Mode of Delivery } \\
\hline Vaginal delivery/IVD & 173 & 73.0 & 122.9 & 9.6 & 95 & 140 & \multirow[t]{2}{*}{$0.17^{a}$} \\
\hline Cesarean delivery & 64 & 27.0 & 120.9 & 10.8 & 81 & 139 & \\
\hline \multicolumn{8}{|l|}{ Delivery location } \\
\hline Hospital & 163 & 68.8 & 121.9 & 10.6 & 81 & 140 & \multirow[t]{2}{*}{$0.27^{\mathrm{a}}$} \\
\hline Public health center/midwifery clinic & 74 & 31.2 & 123.3 & 8.4 & 100 & 138 & \\
\hline \multicolumn{8}{|l|}{ Rooming-in } \\
\hline No & 86 & 36.3 & 120.4 & 9.4 & 98 & 140 & \multirow[t]{2}{*}{$0.02^{a}$} \\
\hline Yes & 151 & 63.7 & 123.5 & 10.1 & 81 & 139 & \\
\hline \multicolumn{8}{|l|}{ Skin-to-skin contact } \\
\hline No & 71 & 30.0 & 119.2 & 10.7 & 81 & 139 & \multirow[t]{2}{*}{$0.001^{\mathrm{a}}$} \\
\hline Yes & 166 & 70.0 & 123.7 & 9.3 & 95 & 140 & \\
\hline \multicolumn{8}{|l|}{ Breastfeeding self-efficacy } \\
\hline$\leq 50$ & 31 & 13.1 & 111.8 & 10.7 & 81 & 132 & $0.0001^{\mathrm{a}}$ \\
\hline$>50$ & 206 & 86.9 & 123.9 & 8.9 & 95 & 140 & \\
\hline Infant's age (months) & & & & & & & \\
\hline $0 \sim 1$ & 56 & 23.6 & 122.0 & 10.8 & 81 & 139 & $0.31^{b}$ \\
\hline $2 \sim 3$ & 95 & 40.1 & 121.4 & 9.4 & 96 & 139 & \\
\hline $4 \sim 5$ & 86 & 36.3 & 123.6 & 10.0 & 98 & 140 & \\
\hline Infant's gender & & & & & & & \\
\hline Girl & 127 & 53.6 & 121.9 & 10.2 & 81 & 139 & $0.50^{a}$ \\
\hline Boy & 110 & 46.4 & 122.8 & 9.8 & 95 & 140 & \\
\hline Infant's birth weight (g) & & & & & & & \\
\hline$\leq 3000$ & 95 & 40.1 & 121.8 & 9.8 & 96 & 140 & $0.51^{\mathrm{a}}$ \\
\hline$>3000$ & 142 & 59.9 & 122.7 & 10.1 & 81 & 139 & \\
\hline Infant sucking behavior & & & & & & & \\
\hline Negative & 37 & 15.6 & 119.4 & 9.4 & 98 & 134 & $0.05^{\mathrm{a}}$ \\
\hline Positive & 200 & 84.4 & 122.9 & 10.0 & 81 & 140 & \\
\hline
\end{tabular}

Note: IVD instrumental vaginal delivery, SD Standard Deviation, Min Minimum, Max Maximum; ${ }^{\mathrm{a}}$-test; ${ }^{\mathrm{b}}$ one-way ANOVA 
Table 4 Multiple linear regression analysis of perceived milk supply $(N=237)$

\begin{tabular}{|c|c|c|c|c|c|c|}
\hline Variable & $n$ & $\%$ & $\beta$ & $S E$ & Standardized $\beta$ & $p$ value \\
\hline Intercept & & & 89.9 & 5.37 & & $<0.0001$ \\
\hline \multicolumn{7}{|c|}{ Employment status } \\
\hline Not working & 173 & 73.0 & Reference & & & \\
\hline Working & 64 & 27.0 & -0.96 & 1.36 & -0.04 & 0.48 \\
\hline \multicolumn{7}{|l|}{ Parity } \\
\hline Primiparous & 95 & 40.1 & Reference & & & \\
\hline Multiparous & 142 & 59.9 & 0.89 & 1.21 & 0.04 & 0.46 \\
\hline \multicolumn{7}{|l|}{ Rooming-in } \\
\hline No & 86 & 36.3 & Reference & & & \\
\hline Yes & 151 & 63.7 & 1.69 & 1.25 & 0.08 & 0.18 \\
\hline \multicolumn{7}{|c|}{ Skin-to-skin contact } \\
\hline No & 71 & 30.0 & Reference & & & \\
\hline Yes & 166 & 70.0 & 3.20 & 1.31 & 0.15 & 0.02 \\
\hline \multicolumn{7}{|c|}{ Breastfeeding self-efficacy } \\
\hline$\leq 50$ & 31 & 13.1 & Reference & & & \\
\hline$>50$ & 206 & 86.9 & 10.78 & 1.81 & 0.37 & $<0.0001$ \\
\hline \multicolumn{7}{|c|}{ Infant sucking behavior } \\
\hline Negative & 37 & 15.6 & Reference & & & \\
\hline Positive & 200 & 84.4 & 2.10 & 1.63 & 0.08 & 0.20 \\
\hline
\end{tabular}

Note: SE standard error

milk sufficiency as reported by earlier research in Japanese mothers [12]. A recent meta-analysis indicates that educational interventions targeting breastfeeding selfefficacy may alleviate perceptions of breast milk insufficiency and improve breastfeeding outcomes [35]. These findings once again support that mothers' participation in Baby-Friendly practice (i.e., skin-to-skin contact and rooming-in) had better perception of breast milk sufficiency [36].

\section{The relation between perceived milk supply and breastfeeding practice}

In the present study, we found that mothers who had a high perception of sufficient breast milk were more likely to exclusively breastfeed, but tended not to practice early initiation of breastfeeding. Prior studies conducted in India and Bangladesh [37-39] reported that mothers with a perception of insufficient milk tended to delay initiation of breastfeeding. The different findings might be partly explained by the existence of cultural beliefs about breast milk. For example, the belief that colostrum is harmful for the newborn [38, 39] or the early introduction of prelacteal feeding might infect the baby's gut may lead mothers to delay initiation of breastfeeding [39]. Such cultural beliefs about breast milk are common for delayed breastfeeding in Indonesia [40].
The majority (90.3\%) of our participants were Islamic, who obeyed the teaching of breastfeeding babies for first 2 years (The Quran verse 2:233). The infant's father has the responsibility to support breastfeeding under all circumstances. Providing a shelter and financial support for breastfeeding is required should a divorce occurs (verses 2:233 and 65:6) [41]. It is possible that such a religious belief contributes to the high rate of exclusive breastfeeding in our study.

\section{Relevance to clinical practice}

Results of this study have important implications for healthcare practices both in clinical and community settings. Health professionals, especially nurses, might consider assessing perceived milk supply in antenatal or postpartum care to identify and provide support promptly to mothers who perceive they have insufficient milk. Antenatal breastfeeding interventions based on breastfeeding self-efficacy have been suggested as an effective strategy for increasing mother's confidence [42, 43] and could be used to eliminate barriers due to misconceptions. Professional support in hospitals (e.g., skinto-skin contact, the rooming-in practice, and lactation counselling) guided by the Ten Steps to Successful Breastfeeding will be helpful for mothers during hospital stay when mothers' decisions on weaning or supplementing breastfeeding are made [44, 45]. It is also important to collaborate with multiple sectors in health systems, service providers, community health workers, stakeholders, and policymakers [35] to support women with breastfeeding needs in order to ensure successful and continuous breastfeeding.

\section{Limitations}

Several limitations should be considered when interpreting results of this study. First, the cross-sectional study design only allows an interpretation of the correlations between perceived milk supply and breastfeeding practices and thus causal effects among the variables cannot be drawn. Researchers could consider conducting longitudinal studies to examine potential causal relationships in future studies. Second, our sample only contained healthy women and was conducted in the Java island region of Yogyakarta city in Indonesia focusing on mothers receiving care from the PHCs, not the inhospital mothers. Future studies need to include mothers at risk and mothers from large number of PHCs or hospitals in Indonesia to increase the heterogeneity of the sample. Third, the self-reported data pertaining to the postpartum period (e.g., early initiation of breastfeeding, skin-to-skin contact) were collected retrospectively and thus may be subject to recall bias. In this study, mothers' perception of their milk supply was measured using a self-reporting scale. The actual amount of 
Table 5 Logistic regression analysis of perceived milk supply, early initiation of breastfeeding and exclusive breastfeeding $(N=237)$

\begin{tabular}{|c|c|c|c|c|c|c|}
\hline \multirow[t]{2}{*}{ Variable } & \multicolumn{3}{|c|}{ Early initiation of breastfeeding } & \multicolumn{3}{|c|}{ Exclusive breastfeeding } \\
\hline & $n$ & $\%$ & OR $(95 \% \mathrm{Cl})$ & $n$ & $\%$ & OR $(95 \% \mathrm{Cl})$ \\
\hline \multicolumn{7}{|l|}{ Univariate analysis } \\
\hline \multicolumn{7}{|l|}{ Perceived milk supply } \\
\hline$\leq 122$ & 35 & 29.9 & 1.00 & 56 & 47.9 & 1.00 \\
\hline$>122$ & 46 & 38.3 & $1.46(0.85,2.50)$ & 92 & 76.7 & $3.58(2.05,6.25)^{* * *}$ \\
\hline \multicolumn{7}{|l|}{ Multivariate analysis } \\
\hline \multicolumn{7}{|l|}{ Perceived milk supply } \\
\hline$\leq 122$ & 35 & 29.9 & 1.00 & 56 & 47.9 & 1.00 \\
\hline$>122$ & 46 & 38.3 & $1.84(0.93,3.6)$ & 92 & 76.7 & $3.20(1.76,5.83)^{* * *}$ \\
\hline \multicolumn{7}{|l|}{ Educational level } \\
\hline High school and less & 50 & 31.4 & 1.00 & 105 & 66.0 & 1.00 \\
\hline College and above & 31 & 39.7 & $1.84(0.96,3.64)$ & 43 & 55.1 & $0.73(0.38,1.39)$ \\
\hline \multicolumn{7}{|l|}{ Employment status } \\
\hline Not working & 55 & 31.8 & 1.00 & 117 & 67.6 & 1.00 \\
\hline Working & 26 & 40.6 & $1.53(0.75,3.15)$ & 31 & 48.4 & $0.47(0.24,0.93)^{*}$ \\
\hline \multicolumn{7}{|l|}{ Mode of delivery } \\
\hline Vaginal delivery & 77 & 44.5 & 1.00 & 117 & 67.6 & 1.00 \\
\hline Cesarean delivery & 4 & 6.3 & $0.13(0.04,0.41)^{* * *}$ & 31 & 48.4 & $0.82(0.38,1.79)$ \\
\hline \multicolumn{7}{|l|}{ Delivery location } \\
\hline Hospital & 47 & 28.8 & 1.00 & 96 & 58.9 & 1.00 \\
\hline Public health center/midwifery clinic & 34 & 45.9 & $1.36(0.71,2.60)$ & 52 & 70.3 & $1.14(0.57,2.28)$ \\
\hline \multicolumn{7}{|l|}{ Rooming-in } \\
\hline No & 22 & 25.6 & 1.00 & 47 & 54.7 & 1.00 \\
\hline Yes & 59 & 39.1 & $1.21(0.61,2.38)$ & 101 & 66.9 & $1.12(0.60,2.08)$ \\
\hline \multicolumn{7}{|l|}{ Skin-to-skin contact } \\
\hline No & 8 & 11.3 & 1.00 & 31 & 43.7 & 1.00 \\
\hline Yes & 73 & 44.0 & $2.81(1.14,6.91)^{*}$ & 117 & 70.5 & $2.36(1.13,4.91)^{*}$ \\
\hline
\end{tabular}

Note: $O R$ odds ratio, $C l$ confidence interval; ${ }^{*} p<0.05 ;{ }^{* *} p<0.01 ;{ }^{* * *} p<0.0001$

milk supply was not measured due to the lack of available tools in this study. Future researchers could consider exploring the associations between mothers' perception of their milk supply and their actual amount of milk supply and examine whether the related factors remain associated with maternal perception of milk supply and actual milk supply.

\section{Conclusions}

Mothers who practiced skin-to-skin contact and had high self-efficacy in breastfeeding tended to have higher levels of perceived milk supply, and a perception of sufficient milk supply was linked to higher odds of exclusive breastfeeding. Our study highlights the importance of the prompt assessment for mother's perception of milk supply during the postpartum stage. These findings are helpful in guiding the development of effective interventions in clinical and community settings. The health care professionals can then provide these interventions to assist optimal breastfeeding practices for mothers in developing countries where exclusive breastfeeding is essential for infant health.

\section{Acknowledgements}

We would like to thank all mothers who participated in the study.

\section{Authors' contributions}

AS designed the study, obtained the data, analyzed the data, wrote the first draft, and revised the manuscript. GTL interpreted the data, critically read the entire manuscript, and revised the manuscript. RC critically read the entire manuscript and revised the manuscript. $\mathrm{MH}$ critically read the entire manuscript and revised the manuscript. SK designed the study, guided the analysis, and directed and revised the manuscript. All authors read and approved the final manuscript.

\section{Funding}

This study was supported by the Ministry of Science and Technology, Taiwan (MOST 107-2314-B-038-034; MOST 106-2314-B-038-012; MOST 104-2314-B038-008). The contents are solely the responsibility of the authors and do not necessarily represent the funders. The funders had no role in the study design, data collection and analysis, decision to publish, or preparation of the manuscript. 


\section{Availability of data and materials}

The datasets used and analyzed during the current study are available from the corresponding author on reasonable request.

\section{Ethics approval and consent to participate}

The study was approved by the Institutional Review Board of Universitas Gadjah Mada, Indonesia (IRB number: KE/FK/1044/EC/2015). Written informed consent was obtained from each mother before participation.

\section{Consent for publication}

Not applicable.

\section{Competing interests}

All authors have declared no potential conflicts of interest regarding the research.

\section{Author details}

'Department of Pediatric and Maternity Nursing, Faculty of Medicine, Public Health and Nursing, Universitas Gadjah Mada, Yogyakarta, Indonesia. ${ }^{2}$ School of Nursing, College of Nursing, Taipei Medical University, Taipei, Taiwan. ${ }^{3}$ Applied Psychology, Faculty of Education, Western University, London, ON Canada.

Received: 7 January 2020 Accepted: 13 July 2020

Published online: 17 July 2020

\section{References}

1. Kramer MS, Kakuma R. Optimal duration of exclusive breastfeeding. Cochrane Database Syst Rev. 2012:8:CD003517.

2. Binns CW, Lee MK. Exclusive breastfeeding for six months: the WHO six months recommendation in the Asia Pacific region. Asia Pac J Clin Nutr. 2014;23(3):344-50.

3. Victora CG, Bahl R, Barros AJ, Franca GV, Horton S, Krasevec J, et al. Breastfeeding in the 21st century: epidemiology, mechanisms, and lifelong effect. Lancet. 2016;387(10017):475-90.

4. Indonesian Ministry of Health. The Primary Results of 2018 Basic Health Research. 2018. http://www.depkes.go.id/resources/download/info-terkini/ materi_rakorpop_2018/ Hasil\%20Riskesdas\%202018.pdf. Accessed 30 Dec 2018.

5. Shetty P. Indonesia's breastfeeding challenge is echoed the world over. Bull World Health Organ. 2014;92:234-5

6. Labbok MH. Global baby-friendly hospital initiative monitoring data: update and discussion. Breastfeed Med. 2012:7:210-22

7. Flaherman VJ, Chan S, Desai R, Agung FH, Hartati H, Yelda F. Barriers to exclusive breast-feeding in Indonesian hospitals: a qualitative study of early infant feeding practices. Public Health Nutr. 2018;21(14):2689-97.

8. Hill PD, Humenick SS. Development of the H \& H Lactation Scale. Nurs Res. 1996:45(3):136-40

9. Sacco LM, Caulfield LE, Gittelsohn J, Martinez H. The conceptualization of perceived insufficient milk among Mexican mothers. J Hum Lact. 2006;22(3): 277-86.

10. Kent JC, Prime DK, Garbin CP. Principles for maintaining or increasing breast milk production. J Obstet Gynecol Neonatal Nurs. 2012;41(1):114-21.

11. Sharma IK, Byrne A. Early initiation of breastfeeding: a systematic literature review of factors and barriers in South Asia. Int Breastfeed J. 2016;11:17.

12. Otsuka K, Dennis $\mathrm{CL}$, Tatsuoka $\mathrm{H}$, Jimba M. The relationship between breastfeeding self-efficacy and perceived insufficient milk among Japanese mothers. J Obstet Gynecol Neonatal Nurs. 2008:37(5):546-55.

13. Walburg V, Goehlich M, Conquet M, Callahan S, Scholmerich A, Chabrol H. Breast feeding initiation and duration: comparison of French and German mothers. Midwifery. 2010;26(1):109-15.

14. Gatti L. Maternal perceptions of insufficient milk supply in breastfeeding. J Nurs Scholarsh. 2008:40(4):355-63.

15. Huang YY, Lee JT, Huang CM, Gau ML. Factors related to maternal perception of milk supply while in the hospital. J Nurs Res. 2009;17(3):17988.

16. Bramson L, Lee JW, Moore E, Montgomery S, Neish C, Bahiri K, et al. Effect of early skin-to-skin mother--infant contact during the first 3 hours following birth on exclusive breastfeeding during the maternity hospital stay. J Hum Lact. 2010;26(2):130-7.
17. Health Agency of Yogyakarta City. Yogyakarta City Health Profile. Yogyakarta: Health Agency of Yogyakarta City; 2009.

18. Lin SY, Lee JT, Yang CC, Gau ML. Factors related to milk supply perception in women who underwent cesarean section. J Nurs Res. 2011;19(2):94-101.

19. Dennis CL. The breastfeeding self-efficacy scale: psychometric assessment of the short form. J Obstet Gynecol Neonatal Nurs. 2003;32(6):734-44.

20. Mizuno K, Fujimaki K, Sawada M. Sucking behavior at breast during the early newborn period affects later breast-feeding rate and duration of breast-feeding. Pediatr Int. 2004;46(1):15-20.

21. Wild D, Grove A, Martin M, Eremenco S, McElroy S, Verjee-Lorenz A, et al. Principles of good practice for the translation and cultural adaptation process for patient-reported outcomes (PRO) measures: report of the ISPOR task force for translation and cultural adaptation. Value Health. 2005;8(2):94104.

22. Nanishi K, Green J, Taguri M, Jimba M. Determining a cut-off point for scores of the breastfeeding self-efficacy scale-short form: secondary data analysis of an intervention study in Japan. PLoS One. 2015;10(6):e0129698.

23. World Health Organization. Indicators for assessing infant and young child feeding practices: part 1: definitions: conclusions of a consensus meeting held 6-8 November 2007 in Washington DC, USA. 2008.

24. Ananta Y, Gandaputra E, Waiman E, Partiwi IGAN, Marzuki NS, Yohmi E, et al. Exclusive breastfeeding rate and factors associated with infant feeding practices in Indonesia. Paediatrica Indonesiana. 2016;56(1):24-31.

25. Oktaria V, Lee K, Bines JE, Watts E, Satria CD, Atthobari J, et al. Nutritional status, exclusive breastfeeding and management of acute respiratory illness and diarrhea in the first 6 months of life in infants from two regions of Indonesia. BMC Pediatr. 2017:17:211.

26. Yulianingsih. Yogyakarta Arranges Regional Regulation on Exclusive Breastfeeding. http://nasional.republika.co.id/berita/nasional/jawa-tengahdiy-nasional/13/02/18/mifayl-yogya-susun-perda-pemberian-asi-eksklusif. Accessed 24 May 2013.

27. Camurdan AD, Ithan MN, Beyazova U, Sahin F, Vatandas N, Eminoglu S. How to achieve long-term breast-feeding: factors associated with early discontinuation. Public Health Nutr. 2008;11(11):1173-9.

28. Herdianto. 10 Myths and Facts About Breastfeeding. http://1health.id/en/ article/ category/product-info/10-myths-and-facts-about-breastfeeding-1103. html. Accessed 28 Dec 2015.

29. Moore ER, Bergman N, Anderson GC, Medley N. Early skin-to-skin contact for mothers and their healthy newborn infants. Cochrane Database Syst Rev. 2016;11:CD003519.

30. Bergmann RL, Bergmann KE, von Weizsacker K, Berns M, Henrich W, Dudenhausen JW. Breastfeeding is natural but not always easy: intervention for common medical problems of breastfeeding mothers - a review of the scientific evidence. J Perinat Med. 2014;42(1):9-18.

31. Essa RM, Ismail NIAA. Effect of early maternal/newborn skin-to-skin contact after birth on the duration of third stage of labor and initiation of breastfeeding. J Nurs Educ Practice. 2015;5(4):98-107.

32. Linares AM, Wambach K, Rayens MK, Wiggins A, Coleman E, Dignan MB. Modeling the influence of early skin-to-skin contact on exclusive breastfeeding in a sample of Hispanic immigrant women. J Immigr Minor Health. 2017:19(5):1027-34.

33. Beal JA, Dalton MF, Maloney JA. Should mother-baby rooming-in be the standard of care? Am J Matern Child Nurs. 2015;40(2):74-5.

34. Jaafar SH, Lee KS, Ho JJ. Separate care for new mother and infant versus rooming-in for increasing the duration of breastfeeding. Cochrane Database Syst Rev. 2012;9:CD006641.

35. Sinha B, Chowdhury R, Sankar MJ, Martines J, Taneja S, Mazumder S, et al. Interventions to improve breastfeeding outcomes: a systematic review and meta-analysis. Acta Paediatr. 2015;104(467):114-34.

36. UNICEF. Exclusive breastfeeding, means breast milk, and nothing else. http://www.unicef.org/indonesia/reallives_19397.html. Accessed 22 Oct 2012

37. Moran AC, Choudhury N, Zaman U, Khan N, Ahsan Karar Z, Wahed T, Faiz Rashid S, et al. Newborn care practices among slum dwellers in Dhaka, Bangladesh: a quantitative and qualitative exploratory study. BMC Pregnancy Childbirth. 2009;9:54.

38. Haider R, Rasheed S, Sanghvi TG, Hassan N, Pachon H, Islam S, et al. Breastfeeding in infancy: identifying the program-relevant issues in Bangladesh. Int Breastfeed J. 2010;5:21.

39. Bandyopadhyay M. Impact of ritual pollution on lactation and breastfeeding practices in rural West Bengal, India. Int Breastfeeding J. 2009;4:2. 
40. Budiati T. Setyowati. The influence culture and maternal care on exclusive breastfeeding practice in post caesarean section mothers. Enfermeria Clinica. 2019;29(Suppl 2):808-14.

41. Shaikh U, Ahmed O. Islam and infant feeding. Breastfeed Med. 2006;1(3): 164-7.

42. Brockway M, Benzies K, Hayden KA. Interventions to improve breastfeeding self-sfficacy and resultant breastfeeding rates: a systematic review and meta-analysis. J Hum Lact. 2017;33(3):486-99.

43. Piro SS, Ahmed HM. Impacts of antenatal nursing interventions on mothers' breastfeeding self-efficacy: an experimental study. BMC Pregnancy Childbirth. 2020;20:19.

44. Pérez-Escamilla R, Martinez $\mathrm{JL}$, Segura-Pérez S. Impact of the baby-friendly hospital initiative on breastfeeding and child health outcomes: a systematic review. Maternal Child Nutr. 2016;12(3):402-17.

45. Rayfield S, Oakley L, Quigley MA. Association between breastfeeding support and breastfeeding rates in the UK: a comparison of late preterm and term infants. BMJ Open. 2015;5(11):e009144.

\section{Publisher's Note}

Springer Nature remains neutral with regard to jurisdictional claims in published maps and institutional affiliations.

Ready to submit your research? Choose BMC and benefit from:

- fast, convenient online submission

- thorough peer review by experienced researchers in your field

- rapid publication on acceptance

- support for research data, including large and complex data types

- gold Open Access which fosters wider collaboration and increased citations

- maximum visibility for your research: over $100 \mathrm{M}$ website views per year

At $\mathrm{BMC}$, research is always in progress.

Learn more biomedcentral.com/submissions 